\title{
MicroRNA-145 inhibits migration and induces apoptosis in human non-small cell lung cancer cells through regulation of the EGFR/PI3K/AKT signaling pathway
}

\author{
BIN LI ${ }^{1}$, CUI-MIN DING ${ }^{1}$, YAN-XIAO LI ${ }^{2}$, JING-CUI PENG $^{1}$, NAN GENG $^{1}$ and WEN-WEN QIN ${ }^{1}$ \\ ${ }^{1}$ Department of Respiratory Medicine, Fourth Hospital of Hebei Medical University; \\ ${ }^{2}$ Department of Respiratory Medicine, First Hospital of Shijiazhuang, Shijiazhuang, Hebei 050011, P.R. China
}

Received July 18, 2017; Accepted July 12, 2018

DOI: 10.3892/or.2018.6666

\begin{abstract}
In the present study, the therapeutic effects and the underlying molecular mechanisms of microRNA (miR)-145 were investigated in non-small cell lung cancer (NSCLC) cells. Reverse transcription-quantitative polymerase chain reaction (RT-qPCR) was performed to examine miR-145 expression. An MTT assay and flow cytometry were used to investigate cell proliferation and apoptosis, respectively. The protein expression of Bax, epidermal growth factor receptor (EGFR), phosphatidylinositol 3-kinase (PI3K) and phosphorylated-protein kinase B (AKT) was examined by western blot analysis. miR-145 expression was downregulated in patients with NSCLC who were treated with chemotherapy. The downregulation of miR-145 in A549 cells reduced lactate dehydrogenase (LDH) expression, apoptosis, caspase-3/-9 levels and Bax protein expression, while it increased cell proliferation. Upregulation of miR-145 in A459 cells increased LDH, apoptosis, caspase-3/-9 levels and Bax protein expression, while it inhibited cell proliferation. The EGFR/PI3K/AKT signaling pathway was suppressed by miR-145 upregulation in A549 cells and induced by miR-145 downregulation. The EGFR inhibitor suppressed the EGFR/PI3K/AKT signaling pathway and increased the anticancer effects of miR-145 upregulation in A549 cells. The PI3K inhibitor suppressed the PI3K/AKT signaling pathway and reversed the anticancer effects of miR-145 upregulation in A549 cells. In conclusion, the present study demonstrated that miR-145 regulates the EGFR/PI3K/AKT signaling pathway in patients with NSCLC.
\end{abstract}

Correspondence to: Dr Bin Li, Department of Respiratory Medicine, Fourth Hospital of Hebei Medical University, 12 JianKang Road, Shijiazhuang, Hebei 050011, P.R. China

E-mail: bxrk93124@126.com

Key words: microRNA-145, epidermal growth factor receptor, phosphatidylinositol 3-kinase, protein kinase B, non-small cell lung cancer cells

\section{Introduction}

Lung cancer is the primary type of malignant tumor that threatens human health; it accounts for the majority of cancer mortalities worldwide and $80 \%$ of cases have non-small cell lung cancer (NSCLC) pathology (1). Although improvements to diagnostic and treatment methods have greatly improved the rate of early diagnosis for NSCLC and provided guidance for personalized treatment, $\sim 66 \%$ of patients are diagnosed when the disease has reached an advanced stage (2). Late diagnosis limits the effectiveness of first-line treatment to chemotherapy and the expected survival time for these patients is $\sim 8$ months. Research into the molecular phenotypes of lung cancer contribute to more accurate early diagnoses, advanced molecular classification and improved prognosis estimates (3). The molecular network underlying the development of lung cancer has been partially identified at the protein and gene level. Over the past 10 years, gene therapy based on the underlying molecular network of lung cancer development has advanced, however, the overall 5-year mortality rate for patients with lung cancer has not significantly improved (4).

Platinum-based chemotherapy regimens are the first-line treatment against NSCLC; however, the body may rapidly develop resistance to platinum drugs, which is a key obstacle in the clinical treatment of NSCLC (5). Platinum resistance is generally considered to be caused by multiple factors, including resistance-associated genetic changes, reduced drug accumulation, increased drug detoxication, enhanced apoptosis inhibition and DNA repair capacity, which involve multiple signaling pathways and numerous key factors (6). Recently, microRNAs (miRNAs) have been identified as a novel, alternative pathway for research into tumor drug resistance (7). Previous research has indicated that miRNAs are closely associated with the pathogenesis and drug resistance of tumors (7). The upregulation or downregulation of miRNA expression may directly cause the abnormal protein expression of target genes, which ultimately alter drugs for tumor cells through the cellular signaling pathways (8).

Research on the epidermal growth factor receptor (EGFR) signaling pathway tyrosine kinase inhibitor is the most thorough (9). At present, over $90 \%$ of all identified NSCLC EGFR gene mutations are located in the exons of chromosomes 
19-21 (9). EGFR is expressed in epithelial, mesenchymal and neurogenic tissues, which serve a vital role in regulating the proliferation, differentiation and growth of healthy cells. In addition, EGFR is closely associated with tumor cell growth, angiogenesis, tumor metastasis and cell apoptosis inhibition (10). A ligand binds with the N-terminal extracellular domain of EGFR to form a homodimer or heterodimer, which phosphorylates the tyrosine residue in the cell, thereby activating the downstream signaling pathways. These signaling pathways include the RAS/RAF/extracellular signal-regulated kinase/mitogen-activated protein kinase pathway, the phosphoinositide 3-kinase (PI3K)/protein kinase B (AKT) pathway and the signal transducer and activator of transcription 3/5 signal transduction pathway (11). Ligand binding ultimately results in a series of abnormal biological behaviors in tumor cells, including excessive proliferation and invasion, metastasis and angiogenesis (12).

Mutations within the EGFR are an important indicator of NSCLC progression within the Asian population (13). EGFR-tyrosine kinase inhibitors, including gefitinib and erlotinib, have a response rate of $60-80 \%$ when administered to NSCLC patients with EGFR mutation (14). Gefitinib has recently been demonstrated to be clinically effective in patients with NSCLC and brain metastasis, which indicates that EGFR mutations may lead to brain metastases. Therefore, it is important to investigate the association between EGFR mutations and NSCLC brain metastases (13).

The recent identification of a novel class of non-proteincoding miRNA, with no open reading frame, has confirmed that the genomic complexity of cancer far exceeds original expectations (15). miRNAs are a type of small endogenous non-coding RNA with no open reading frame, which are 20-25 nucleotides in length. They may regulate hundreds of target genes at a post-transcriptional level and therefore participate in numerous biological functions, including regulation of cell differentiation, proliferation and apoptosis (16). As miRNAs are regulatory factors of endogenous gene expression, they are also involved in the pathophysiological processes of a number of diseases through the regulation of multiple genes and their genetic networks (16). Previous studies have revealed that miRNAs may participate in tumor development or regression as either an oncogene or tumor-suppressor gene, respectively (8). Zhang et al revealed that miRNA-145 (miR-145), miR-20a, miR-21 and miR-223 in the plasma, are novel biomarkers for screening of early-stage NSCLC. However, the mechanism of miR-145-regulated cell death in NSCLC remains unknown. The aim of the present study was to evaluate the therapeutic effects and the underlying molecular mechanisms of miR-145 in NSCLC by chemotherapy.

\section{Materials and methods}

Cell lines and clinical specimens. The A549 human NSCLC cell line was purchased from the Cancer Research Institute of Hebei Medical University and cultured in Dulbecco's modified Eagle's medium (DMEM; Invitrogen; Thermo Fisher Scientific, Inc., Waltham, MA, USA) supplemented with $10 \%(\mathrm{~m} / \mathrm{v})$ fetal bovine serum (FBS; Gibco; Thermo Fisher Scientific, Inc.), $100 \mathrm{U} / \mathrm{ml}$ penicillin and $100 \mu \mathrm{g} / \mathrm{ml}$ streptomycin at $37^{\circ} \mathrm{C}$ in a $5 \% \mathrm{CO}_{2}$.
The NSCLC samples $(n=6)$ and normal healthy volunteers $(n=6)$ samples were derived from patients undergoing surgical procedures at the Fourth Hospital of Hebei Medical University (Table I). Peripheral blood $(10 \mathrm{ml})$ of NSCLC samples and normal healthy volunteers samples were centrifuged at 2,000 x g for $10 \mathrm{~min}$ at $4^{\circ} \mathrm{C}$ and serum was saved at $-80^{\circ} \mathrm{C}$. All human studies were approved by the Ethics Committee of Fourth Hospital of Hebei Medical University. All patients signed written informed consent forms prior to the study.

RNA extraction and quantitative RT-PCR. Total RNAs were isolated using TRIzol reagent (Thermo Fisher Scientific, Inc.). RT reactions were performed using $10 \mathrm{ng}$ of total RNA samples and GeneChip WT (Takara Biomedical Technology Co.,Ltd., Beijing, China). Quantitative RT-PCR was performed using the standard TaqMan MicroRNA assay protocol on a 7500 Real-Time PCR System (Applied Biosystems; Thermo Fisher Scientific, Inc.) at $95^{\circ} \mathrm{C}$ for $15 \mathrm{~min}$, followed by 45 cycles at $94^{\circ} \mathrm{C}$ for $15 \mathrm{sec}, 55^{\circ} \mathrm{C}$ for $30 \mathrm{sec}$, and $70^{\circ} \mathrm{C}$ for $30 \mathrm{sec}$. The primer sequences were as follows: miR-145 forward, 5'-ATC GTCCAGTTTTCCCAGG-3' and reverse, 5'-CGCCTCCAC ACACTCACC-3'; U6 forward, 5'-ATTGGAACGATACAG AGAAGATT-3' and reverse, 5'-GGAACGCTTCACGAATTT G-3'. The fold change of miRNA-145 was calculated using the $2^{-\Delta \Delta C q}$ equation (17).

Cell transfection. The cells $\left(1 \times 10^{5}\right.$ cells/well $)$ were plated in 6 -well plates and transfected with either miR-145 mimics $(100 \mathrm{~nm})$ or miR-145 inhibitor $(100 \mathrm{~nm}$; both from Sangon Biotech, Co., Ltd., Shanghai, China) using Lipofectamine 2000 (Invitrogen; Thermo Fisher Scientific, Inc.) according to the manufacturer's instructions. After $48 \mathrm{~h}$ of transfection, the cells were collected for the following experiments. In experiments where the EGFR inhibitor or PI3K inhibitor was used, after $4 \mathrm{~h}$ of transfection, the cells were treated with EGFR inhibitor (0.5 nM; cat. no. AEE788; MedChemExpress, Monmouth Junction, NJ, USA) or PI3K inhibitor (1,3-dicaffeoylquinic acid; $10 \mu \mathrm{M}$; Sigma-Aldrich; Merck KGaA, Darmstadt, Germany) for $48 \mathrm{~h}$.

MTT assay and lactic dehydrogenase $(L D H)$ activity. The cells $\left(5 \times 10^{3}\right.$ cells/well) were plated in 96-well plates and MTT $(5 \mathrm{mg} / \mathrm{ml})$ was added to the cells for $4 \mathrm{~h}$ at $37^{\circ} \mathrm{C}$. Subsequently, the MTT solution was removed and DMSO solution was added into the cells for $20 \mathrm{~min}$ at $37^{\circ} \mathrm{C}$. The absorbance was measured using a multi-well plate reader (Tecan Schweiz AG, Maennedorf, Switzerland) at $492 \mathrm{~nm}$.

LDH activity was assessed using an LDH activity kit (Beyotime Institute of Biotechnology, Shanghai, China). The absorbance was measured using a multi-well plate reader (Tecan Schweiz AG) at $450 \mathrm{~nm}$.

Transwell assays. For the cell migration Transwell assays, 24-well plates with $8.0-\mu \mathrm{m}$ pore size polycarbonate membranes $\left(5 \times 10^{4}, 6.5 \mathrm{~mm}\right.$ diameter; Corning Inc., Corning, NY, USA) were used. Serum-free medium $(100 \mu \mathrm{l})$ was seeded into the upper chamber and $600 \mu \mathrm{l}$ medium containing $10 \%$ FBS was added to the bottom chamber. Cell were cultured for $48 \mathrm{~h}$ and fixed with $4 \%$ paraformaldehyde and stained with $0.1 \%$ crystal 
Table I. Basic knowledge of patients with NSCLC.

\begin{tabular}{lcc}
\hline Variables & $\begin{array}{c}\text { Volunteers } \\
(\mathrm{n}=6)\end{array}$ & $\begin{array}{c}\text { NSCLC } \\
(\mathrm{n}=6)\end{array}$ \\
\hline Age (years) & 3 & 3 \\
$\leq 55$ & 3 & 3 \\
$>55$ & & \\
Sex & 0 & 0 \\
Female & 6 & 6 \\
Male & & \\
Tumor size (cm) & 0 & 2 \\
$\leq 3.0$ & 0 & 4 \\
$>3.0$ & & 0 \\
Edmondson grade & 0 & 2 \\
I & 0 & 4 \\
II & 0 & \\
III & & \\
\hline
\end{tabular}

NSCLC, non-small cell lung cancer.

violet. The cells were observed using an optical microscope (Optotech Co., Ltd., Changchun, China).

Flow cytometry $(F C M)$. The cells $\left(1 \times 10^{6}\right.$ cells/well) were plated in 6-well plates, collected and washed twice with PBS before being suspended with $500 \mu 1$ of binding buffer (BD Biosciences, Franklin Lakes, NJ, USA). The cells were stained with $5 \mu$ l of Annexin V-fluorescein isothiocyanate and $5 \mu 1$ of propidium iodide (PI) for $15 \mathrm{~min}$ at room temperature. A BD FACSCalibur flow cytometer (BD Biosciences) was used to detect cell apoptosis.

Western blot analysis and caspase-3/-9 activity levels. Cell were washed and splitted using RIPA lysis buffer (Beyotime Institute of Biotechnology) after centrifugation at $10,000 \mathrm{x} \mathrm{g}$ for $10 \mathrm{~min}$ at $4^{\circ} \mathrm{C}$. The protein concentration was calculated with a Pierce BCA protein assay kit (Thermo Fisher Scientific, Inc., Rockford, IL, USA). Protein (50 $\mu \mathrm{g})$ was separated on $8-10 \%$ SDS-PAGE gels and transferred to polyvinylidene difluoride (PVDF) membranes (EMD Millipore, Bedford, MA, USA). The membranes were blocked with $5 \%$ non-fat milk at room temperature for $1 \mathrm{~h}$ and immunostained with primary antibodies: Bax (1:500; cat. no. sc-6236), EGFR (1:500; sc-71034), PI3K (1:500; cat. no. sc-7174), p-AKT (Ser473; 1:500; cat. no. sc-7985-R) and GAPDH (1:2,000; cat. no. sc-25778; all from Santa Cruz Biotechnology, Inc., Dallas, TX, USA) at $4^{\circ} \mathrm{C}$ overnight. The membranes were then washed three times in TBST, and then incubated with anti-rabbit secondary antibody (1:2,000; cat. no. sc-2030; Santa Cruz Biotechnology, Inc.) at room temperature for $1 \mathrm{~h}$. Subsequently, the membranes were detected with ECL Plus (GE Healthcare, Piscataway, NJ, USA) and quantitatively determined via densitometry with ImageJ software 2.1.4.7 (imagej.nih.gov/).

Protein $(10 \mu \mathrm{g})$ was used to assess caspase- 3 and caspase-9 activity levels using caspase-3/-9 activity kits (Beyotime
Institute of Biotechnology). The absorbance was measured using a multi-well plate reader (Tecan Schweiz AG) at $405 \mathrm{~nm}$.

Statistical analysis. The results were expressed as the mean \pm standard deviation $(n=3)$. Statistical significance of the results between each group was evaluated using one-way ANOVA followed by Tukey's post test. $\mathrm{P}<0.05$ was considered to indicate a statistically significant difference.

\section{Results}

miR-145 expression. Initially gene chip technology was used to measure the expression of miRNAs. It was observed that miR-145 expression was downregulated in the serum of patients with NSCLC compared with normal healthy volunteers (Fig. 1A and B). In addition, miR-145 expression was assessed using RT-PCR. The results revealed that miR-145 expression was downregulated in NSCLC patients compared to normal healthy volunteers (Fig. 1C).

Effect of miR-145 downregulation on cell growth in A549 cells. To confirm the potential role of miR-145 in patients with NSCLC, a miR-145 inhibitor was used to inhibit the expression of miR-145 in A549 cells (Fig. 2A). The miR-145 inhibitor significantly increased cell proliferation (Fig. 2B) and migration (Fig. 2F and G), and reduced LDH activity (Fig. 2C) and apoptosis (Fig. 2D and E) in A549 cells compared with the control group.

Effect of miR-145 downregulation on caspase-3/-9 activity levels and Bax protein expression in A549 cells. miR-145 downregulation resulted in significant inhibition of caspase-3/-9 activity levels and Bax protein expression in A549 cells compared with the control group (Fig. 3).

Effect of miR-145 upregulation on cell growth in A549 cells. miR-145 mimics were used to verify the effect of miR-145 upregulation on cell growth in A549 cells. The miR-145 mimics increased the expression of miR-145 in A549 cells (Fig. 4A). The miR-145 mimics also significantly inhibited cell proliferation (Fig. 4B) and migration (Fig. 4F and G) and induced LDH activity (Fig. 4C) and apoptosis (Fig. 4D and E) in A549 cells.

Effect of miR-145 upregulation on caspase-3/-9 activity levels and Bax protein expression in A549 cells. Caspase-3/-9 levels and Bax protein expression are common indicators of the apoptosis signaling pathway. It was analyzed whether miR-145 upregulation altered caspase-3/-9 activity levels and Bax protein expression in A549 cells. miR-145 upregulation caused a significant promotion in caspase-3/-9 activity levels and Bax protein expression in A549 cells compared with the control group (Fig. 5).

Effects of miR-145 on the EGFR/PI3K/AKT signaling pathway in A549 cells. The underlying mechanism of miR-145 on apoptosis was explored in A549 cells. Gene chip technology revealed that EGFR and PI3K expression were downregulated in A549 cells compared with the control group when miR-145 was overexpressed (Fig. 6A). In addition, miR-145 downregulation significantly induced the EGFR/PI3K/AKT 
A Control 1 Control 2 Control 3 Control 4 Control 5 Control $6{ }_{\text {MicroRNA-28 }}$

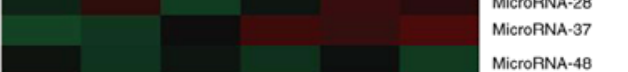

MicroRNA-48 MicroRNA-11 MicroRNA-102 MicroRNA-145 MicroRNA-45 MicroRNA-68

B
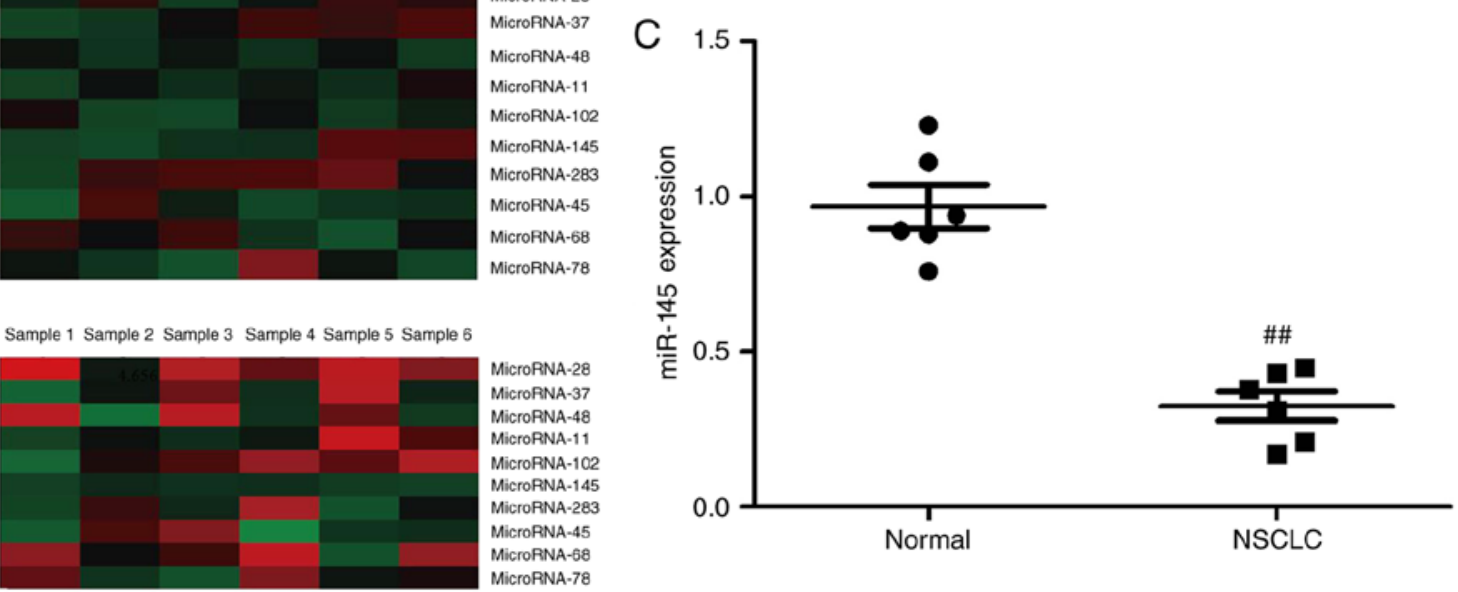

Figure 1. miR-145 expression. MiRNA expression was examined using gene chip technology in (A) normal healthy volunteers and (B) patients with NSCLC. (C) miR-145 expression was also examined using reverse transcription-quantitative polymerase chain reaction. ${ }^{\# \#} \mathrm{P}<0.01$ vs. the control group. NSCLC, non-small cell lung cancer.
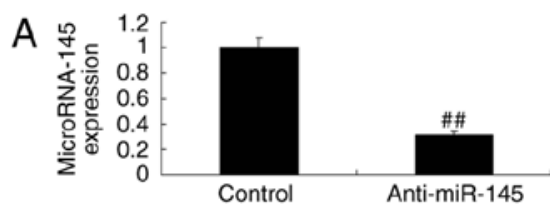

C

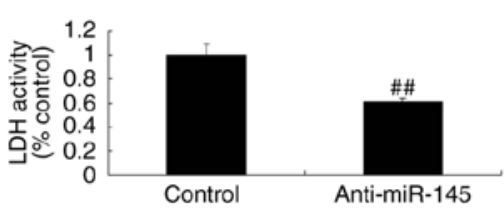

B

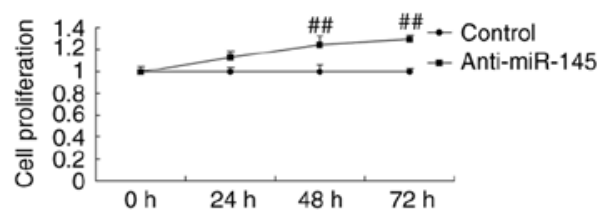

D

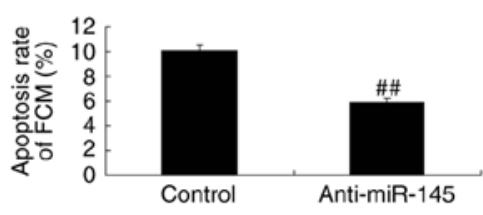

$\mathrm{E}$

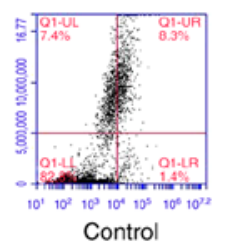

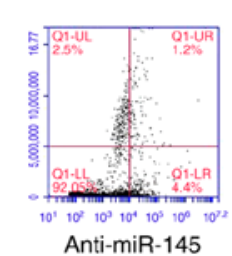

$\mathrm{F}$ )

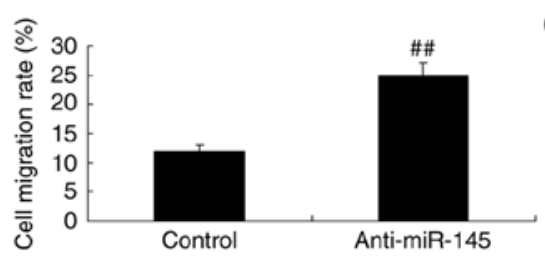

$\mathrm{G}$

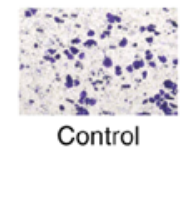

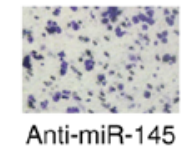

Figure 2. Downregulation of miR-145 on cell growth in A549 cells. (A) miR-145 expression, (B) cell proliferation, (C) LDH activity, (D and E) apoptosis and ( $\mathrm{F}$ and $\mathrm{G})$ migration in A549 cells. The results are expressed as the mean \pm standard deviation $(\mathrm{n}=3)$. ${ }^{\#} \mathrm{P}<0.01 \mathrm{vs}$. the control group. miR, microRNA; LDH, lactate dehydrogenase.

signaling pathway in A549 cells compared with the control group (Fig. 6B-E). The EGFR/PI3K/AKT signaling pathway was significantly suppressed in A459 cells when miR-145 was upregulated, compared with the control group (Fig. 7). These results further demonstrated that miR-145 may serve an important role in A549 cells in vitro.

EGFR inhibitor suppresses the EGFR/PI3K/AKT signaling pathway in A549 cells following miR-145 upregulation. The effect of EGFR on the EGFR/PI3K/AKT signaling pathway was investigated in A549 cells following miR-145 upregulation. The EGFR/PI3K/AKT signaling pathway was significantly suppressed in A549 cells treated with EGFR inhibitor $(0.5 \mathrm{nM}$, $48 \mathrm{~h}$; cat. no. AEE788) following miR-145 upregulation, compared with the miR-145 upregulation group (Fig. 8).
EGFR inhibitor suppresses cell growth in A549 cells following miR-145 upregulation. Significant inhibition of cell proliferation and migration was observed, as well as increases in LDH activity and apoptosis in A549 cells following treatment with miR-145 and EGFR inhibitor, compared with the miR-145 upregulation group (Fig. 9).

EGFR inhibitor suppresses caspase-3/-9 activity levels and Bax protein expression in A549 cells following miR-145 upregulation. A significant promotion in caspase-3/-9 activity levels and Bax protein expression was observed in A549 cells following treatment with miR-145 and the EGFR inhibitor, compared with the miR-145 upregulation group (Fig. 10). These results indicated that EGFR is an important factor, which may enhance the effects of miR-145 on NSCLC chemotherapy. 
A
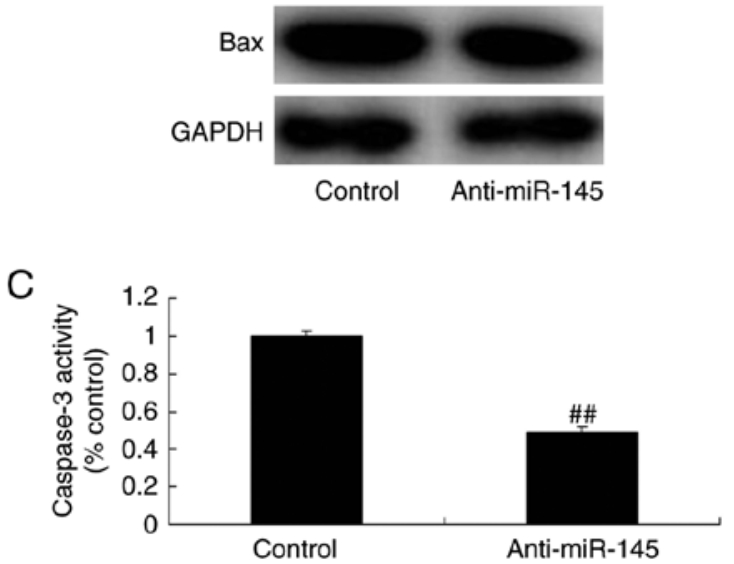

B

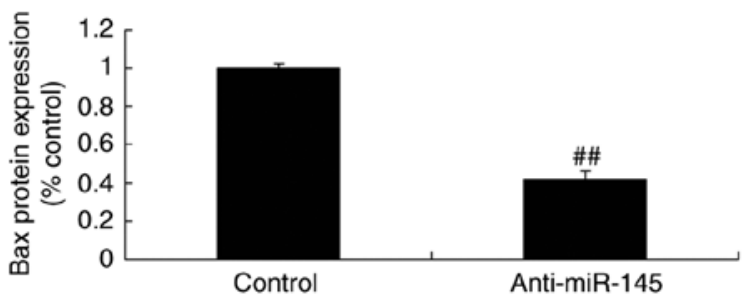

$\mathrm{D}$

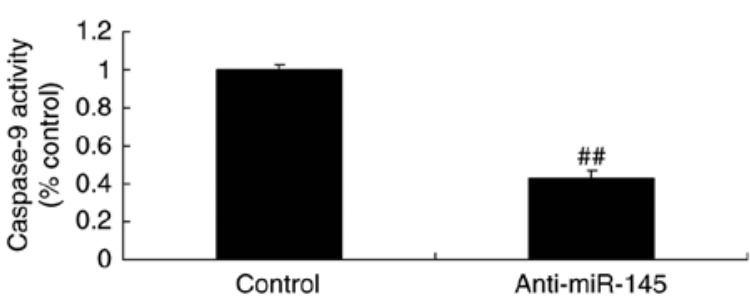

Figure 3. Downregulation of miR-145 on caspase-3/-9 activity levels and Bax protein expression in A549 cells. Bax protein expression was determined using (A) western blot analysis and the results were (B) statistically analyzed. (C and D) Caspase-3/-9 activity levels in A549 cells. The results are expressed as the mean \pm standard deviation $(n=3)$. ${ }^{\# \#} \mathrm{P}<0.01$ vs. the control group. miR, microRNA.
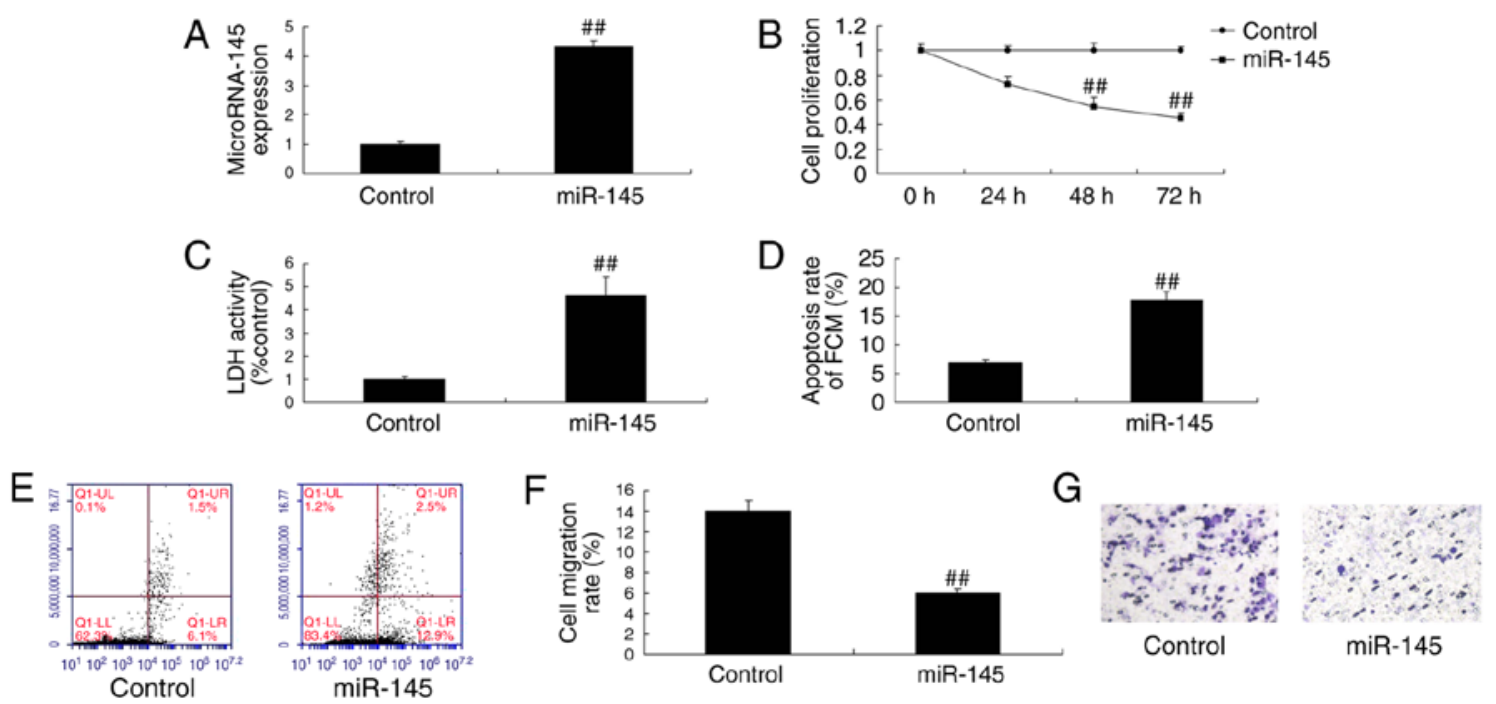

Figure 4. Upregulation of miR-145 on cell growth of A549 cells. (A) miR-145 expression, (B) cell proliferation, (C) LDH activity, (D and E) apoptosis and ( $\mathrm{F}$ and $\mathrm{G})$ migration in A549 cells. The results are expressed as the mean \pm standard deviation $(\mathrm{n}=3)$. ${ }^{\# \#} \mathrm{P}<0.01$ vs. the control group. miR, microRNA; $\mathrm{LDH}$, lactate dehydrogenase.

A

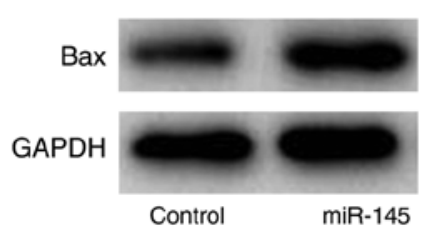

C

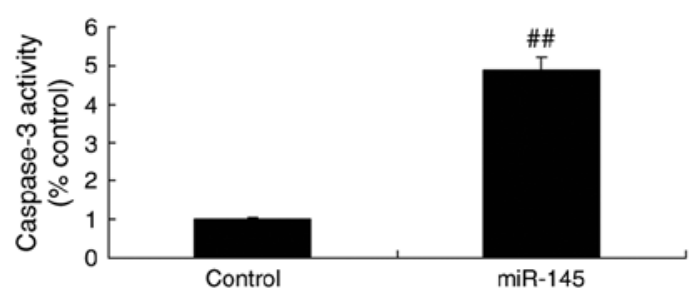

B

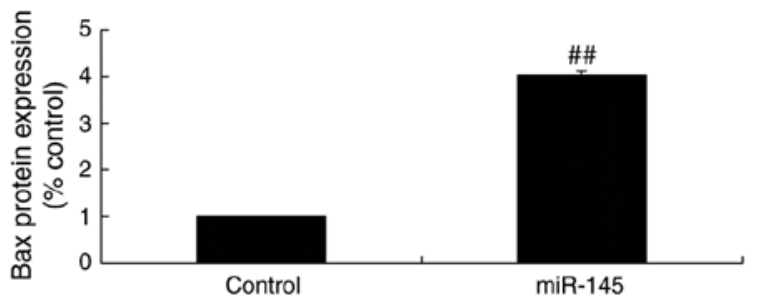

D

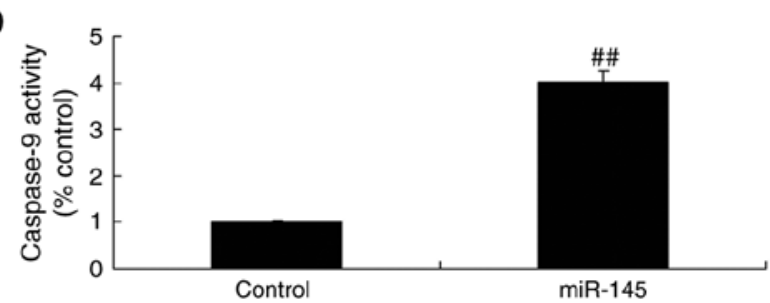

Figure 5. Upregulation of miR-145 on caspase-3/-9 activity levels and Bax protein expression in A549 cells. Bax protein expression was determined using (A) western blot analysis and the results were (B) statistically analyzed. (C and D) Caspase-3/-9 activity levels in A549 cells. The results are expressed as the mean \pm standard deviation $(\mathrm{n}=3)$. ${ }^{\# \#} \mathrm{P}<0.01$ vs. the control group. miR, microRNA. 

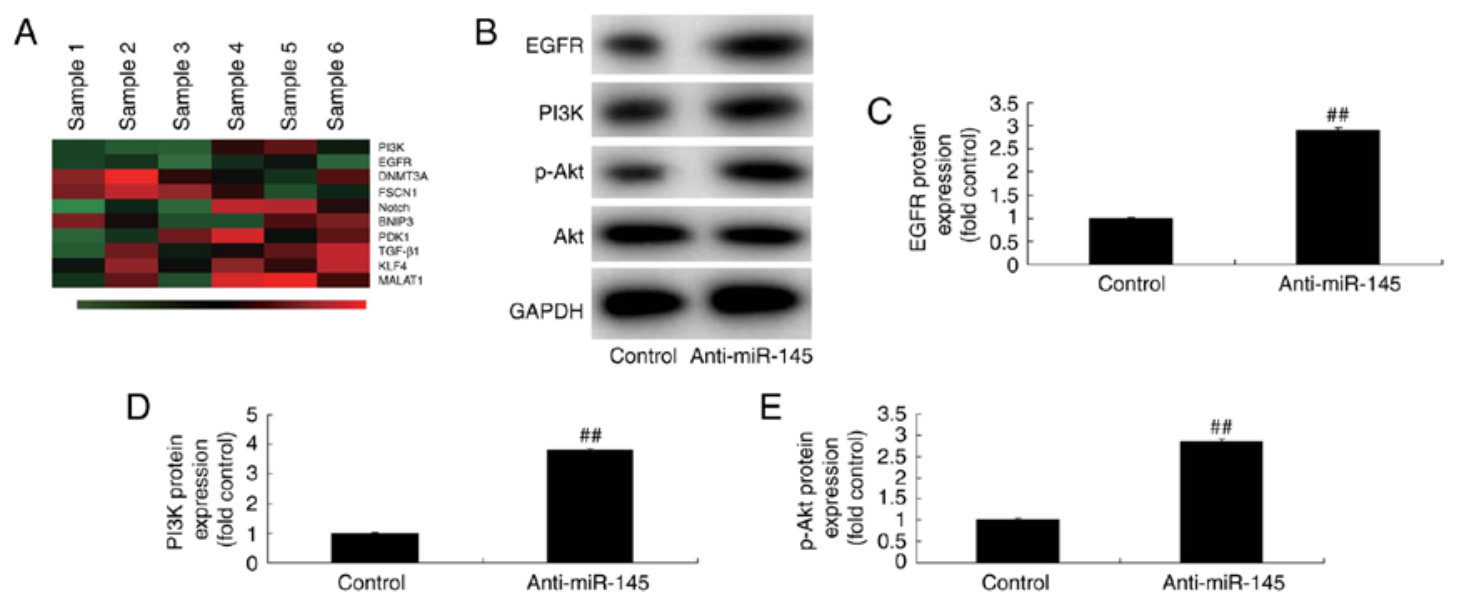

Figure 6. Downregulation of miR-145 on the EGFR/PI3K/AKT signaling pathway in A549 cells. (A) Common signaling pathways were evaluated using gene chip technology. (B) Western blot analysis was performed to determine (C) EGFR, (D) PI3K and (E) p-AKT protein expression in A549 cells. The results are expressed as the mean \pm standard deviation $(\mathrm{n}=3) .{ }^{\# \#} \mathrm{P}<0.01$ vs. the control group. miR, microRNA; EGFR, epidermal growth factor receptor; PI3K, phosphatidylinositol 3-kinase; p-AKT, phosphorylated-protein kinase B.

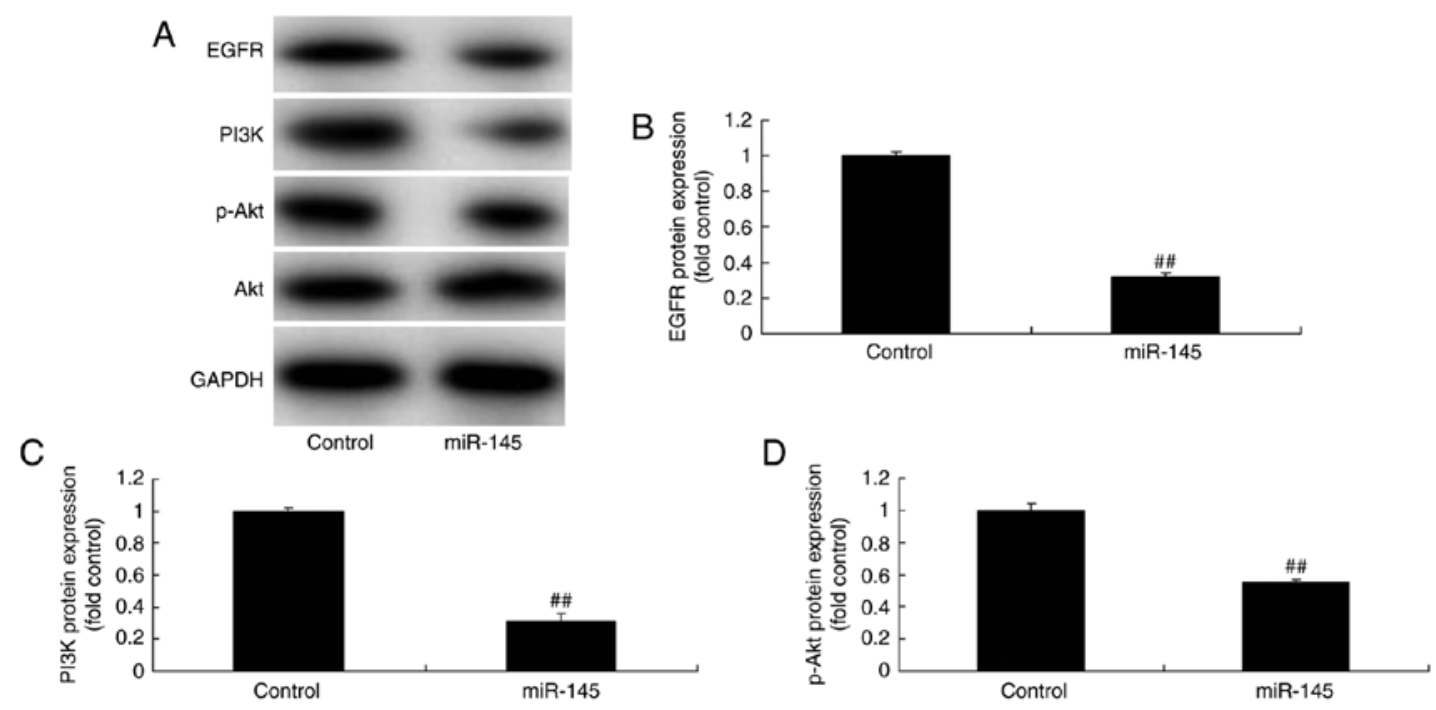

Figure 7. Upregulation of miR-145 on the EGFR/PI3K/AKT signaling pathway in A549 cells. (A) Western blot analysis was performed to determine (B) EGFR, (C) PI3K and (D) p-AKT protein expression in A549 cells. The results are expressed as the mean \pm standard deviation ( $\mathrm{n}=3$ ). ${ }^{\# \#} \mathrm{P}<0.01$ vs. the control group. miR, microRNA; EGFR, epidermal growth factor receptor; PI3K, phosphatidylinositol 3-kinase; p-AKT, phosphorylated-protein kinase B.

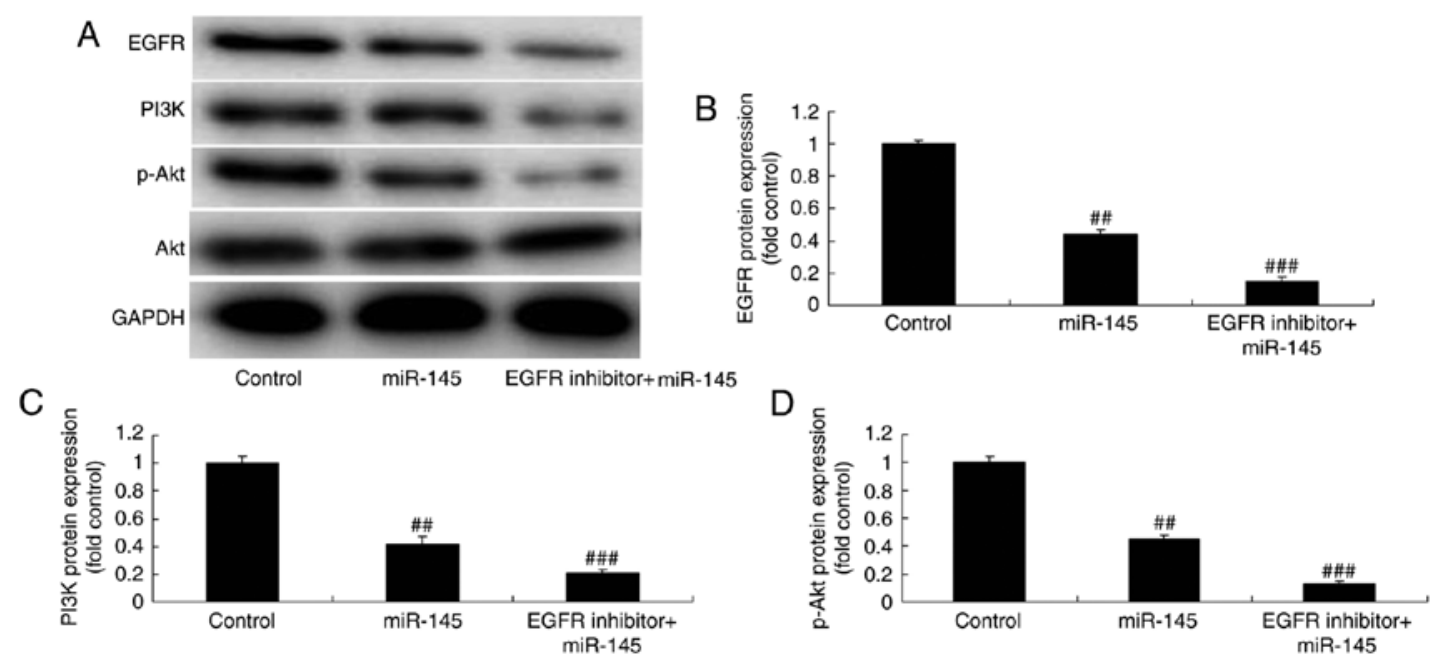

Figure 8. EGFR inhibitor suppresses the EGFR/PI3K/AKT signaling pathway in A549 cells following miR-145 upregulation. (A) Western blot analysis was performed to determine (B) EGFR, (C) PI3K and (D) p-AKT protein expression in A549 cells. The results are expressed as the mean \pm standard deviation $(\mathrm{n}=3) .{ }^{\# /} \mathrm{P}<0.01$ vs. the control group. ${ }^{\# \# /} \mathrm{P}<0.01$ vs. the miR-145-mimic group. miR, microRNA; EGFR, epidermal growth factor receptor; PI3K, phosphatidylinositol 3-kinase; p-AKT, phosphorylated-protein kinase B. 

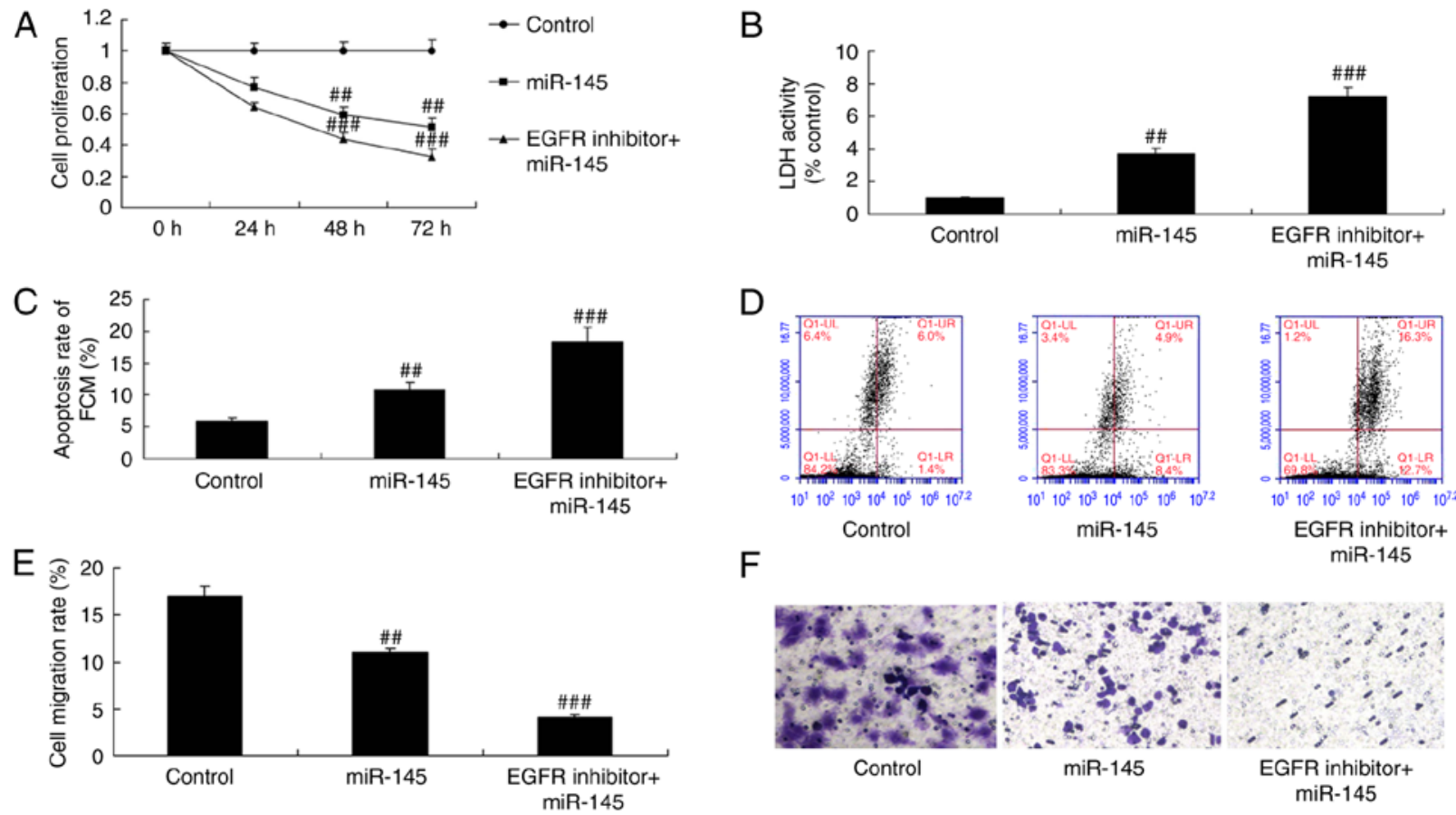

Figure 9. EGFR inhibitor suppresses cell growth in A549 cells following miR-145 upregulation. (A) Cell proliferation, (B) LDH activity, (C and D) apoptosis and ( $\mathrm{E}$ and F) migration in $\mathrm{A} 549$ cells. The results are expressed as the mean \pm standard deviation $(\mathrm{n}=3)$. ${ }^{\# \#} \mathrm{P}<0.01$ vs. the control group. ${ }^{\# \# \#} \mathrm{P}<0.01$ vs. the miR-145-mimic group. miR, microRNA; LDH, lactate dehydrogenase; EGFR, epidermal growth factor receptor.
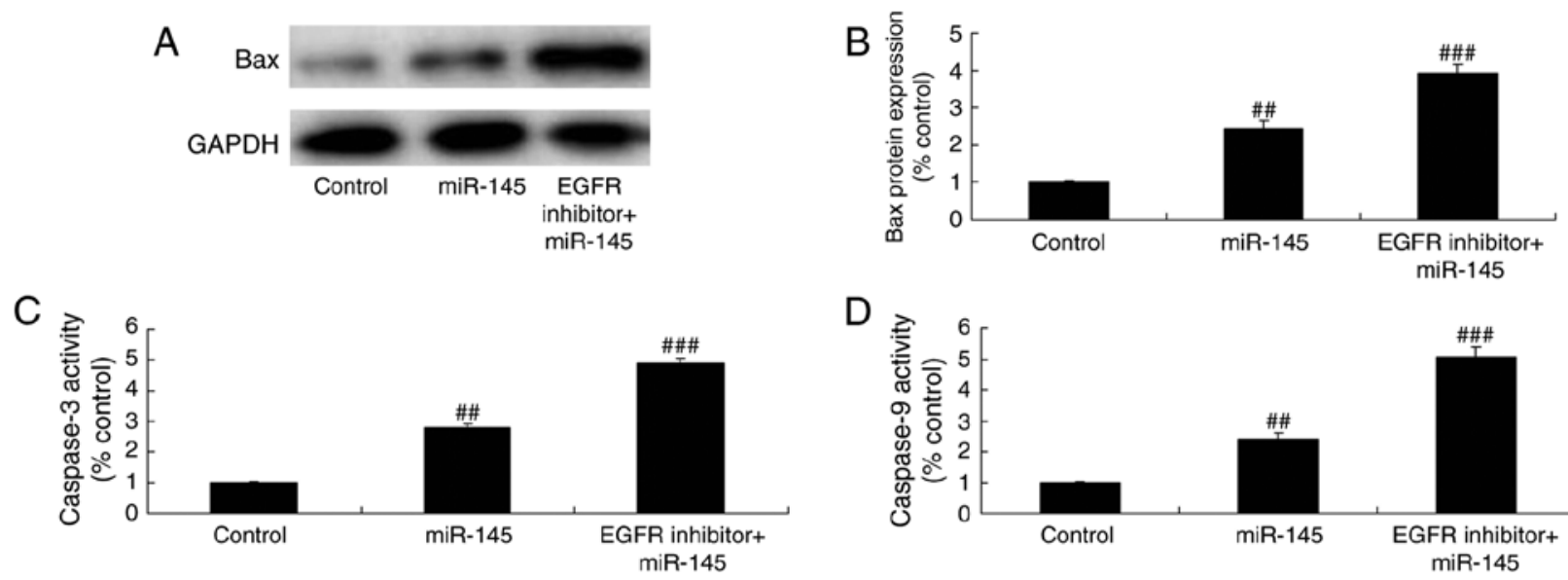

Figure 10. EGFR inhibitor suppresses caspase-3/-9 activity levels and Bax protein expression in A549 cells following miR-145 upregulation. Bax protein expression was determined using (A) western blot analysis and the results were (B) statistically analyzed. (C and D) Caspase-3/-9 activity levels in A549 cells. The results are expressed as the mean \pm standard deviation $(\mathrm{n}=3) .{ }^{\# \#} \mathrm{P}<0.01$ vs. the control group; ${ }^{\# \# P<0.01 ~ v s . ~ t h e ~ m i R-145-m i m i c ~ g r o u p . ~ m i R, ~ m i c r o R N A ; ~}$ EGFR, epidermal growth factor receptor.

PI3K inhibitor suppresses the PI3K/AKT signaling pathway in A549 cells following miR-145 upregulation. The function of PI3K and the effect of miR-145 on the EGFR/PI3K/AKT signaling pathway was investigated in A549 cells. The PI3K inhibitor (1,3-dicaffeoylquinic acid; $10 \mu \mathrm{M}, 48 \mathrm{~h}$ ) significantly suppressed the PI3K/AKT signaling pathway in A549 cells following miR-145 upregulation, compared with the miR-145 upregulation group (Fig. 11).

PI3K inhibitor suppresses cell growth in A549 cells following miR-145 upregulation. The inhibition of PI3K significantly inhibited cell proliferation and migration, while it increased
LDH activity and apoptosis in A549 cells following miR-145 upregulation, compared with the miR-145 upregulation group (Fig. 12).

PI3K inhibitor suppresses caspase-3/-9 activity levels and Bax protein expression in A549 cells following miR-145 upregulation. The inhibition of PI3K significantly increased the effects of miR-145 on caspase-3/-9 activity levels and Bax protein expression in A549 cells, compared with the miR-145 upregulation group (Fig. 13). The aforementioned results indicated that the effects of miR-145 occur through the inhibition of the PI3K/AKT signaling pathway in NSCLC. 

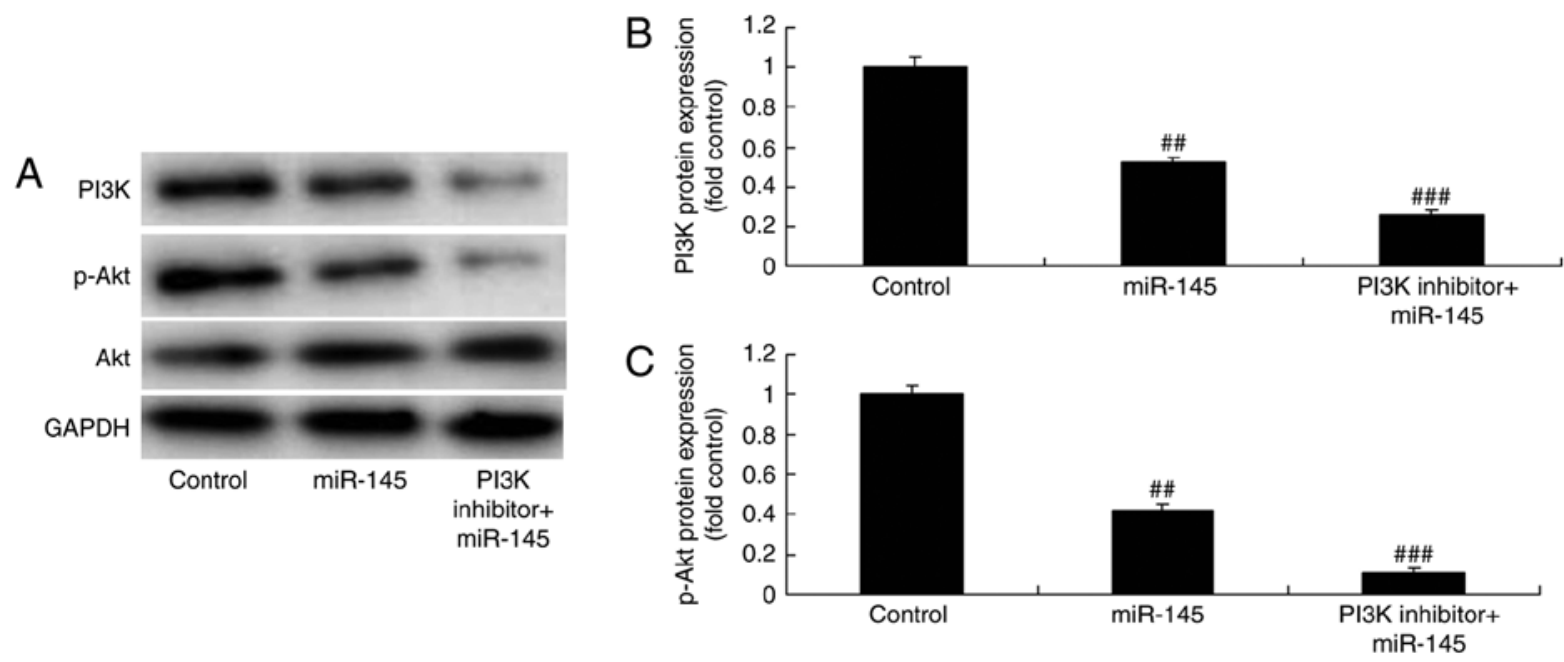

Figure 11. PI3K inhibitor suppresses the PI3K/AKT signaling pathway in A549 cells following miR-145 upregulation. (A) Western blot analysis was performed to determine the protein expression of (B) PI3K and (C) p-AKT in A549 cells. The results are expressed as the mean \pm standard deviation ( $\mathrm{n}=3$ ). ${ }^{\# \#} \mathrm{P}<0.01 \mathrm{vs}$. the control group. ${ }^{\# \#} \mathrm{P}<0.01$ vs. the miR-145-mimic group. miR, microRNA; EGFR, epidermal growth factor receptor; PI3K, phosphatidylinositol 3-kinase; p-AKT, phosphorylated-protein kinase B.

A

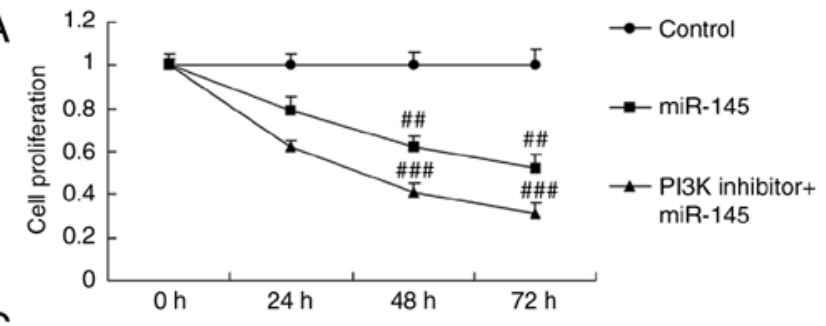

C

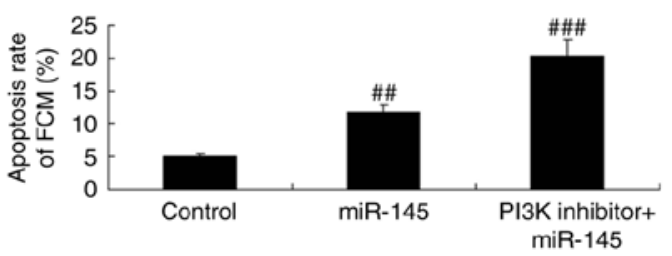

E

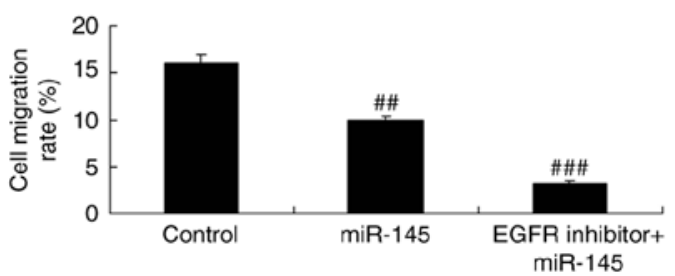

B

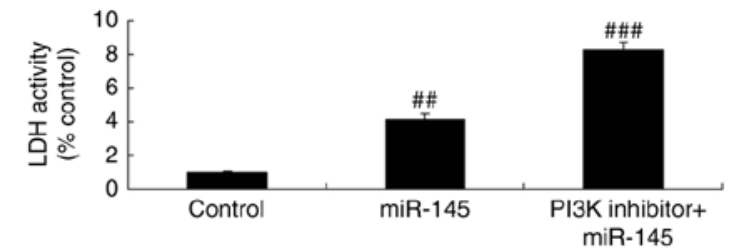

D

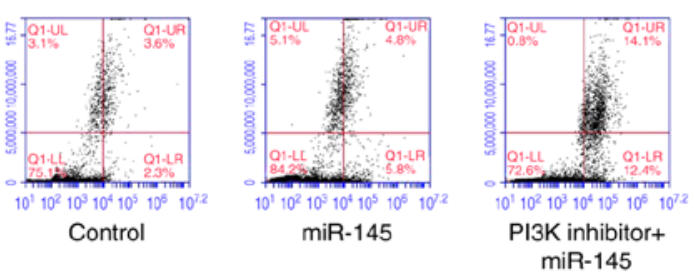

F

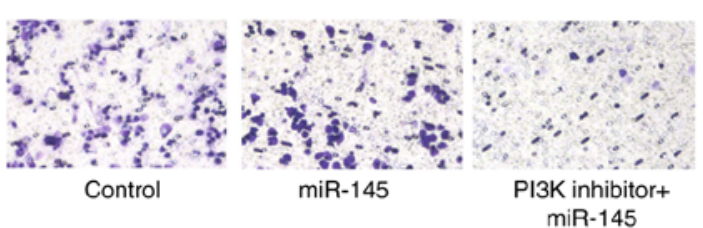

Figure 12. PI3K inhibitor suppresses cell growth in A549 cells following miR-145 upregulation. (A) Cell proliferation, (B) LDH activity, (C and D) apoptosis and (E and F) migration in A549 cells. The results are expressed as the mean \pm standard deviation $(\mathrm{n}=3)$. ${ }^{\# \#} \mathrm{P}<0.01$ vs. the control group. ${ }^{\# \# \# ~} \mathrm{P}<0.01$ vs. the miR-145-mimic group. miR, microRNA; LDH, lactate dehydrogenase; PI3K, phosphatidylinositol 3-kinase.

\section{Discussion}

At present, the principal methods of lung cancer classification and staging used within a clinical setting are primarily based on imaging diagnoses, and morphological changes in tissues and cells observed under a microscope (18). However, these diagnostic methods provide limited information and are insufficient for an accurate and in depth understanding of the molecular changes taking place during tumor genesis and development (1). Therefore, research into the molecular classification of lung cancer may contribute to more targeted treatments and accurate prognosis (4). The present study revealed that miR-145 expression was downregulated in patients with NSCLC compared with normal healthy volunteers, however there were only a total of six individuals in each group, which is a small sample size and represents a limitation of the study. Future studies should analyze data from larger groups to increase the validity of the results. The results of the present study demonstrated that the downregulation of miR-145 in A549 cells reduced LDH and apoptosis, increased cell proliferation, and inhibited caspase-3/-9 levels and Bax protein expression. Zhu et al (19) revealed that miR-122, 

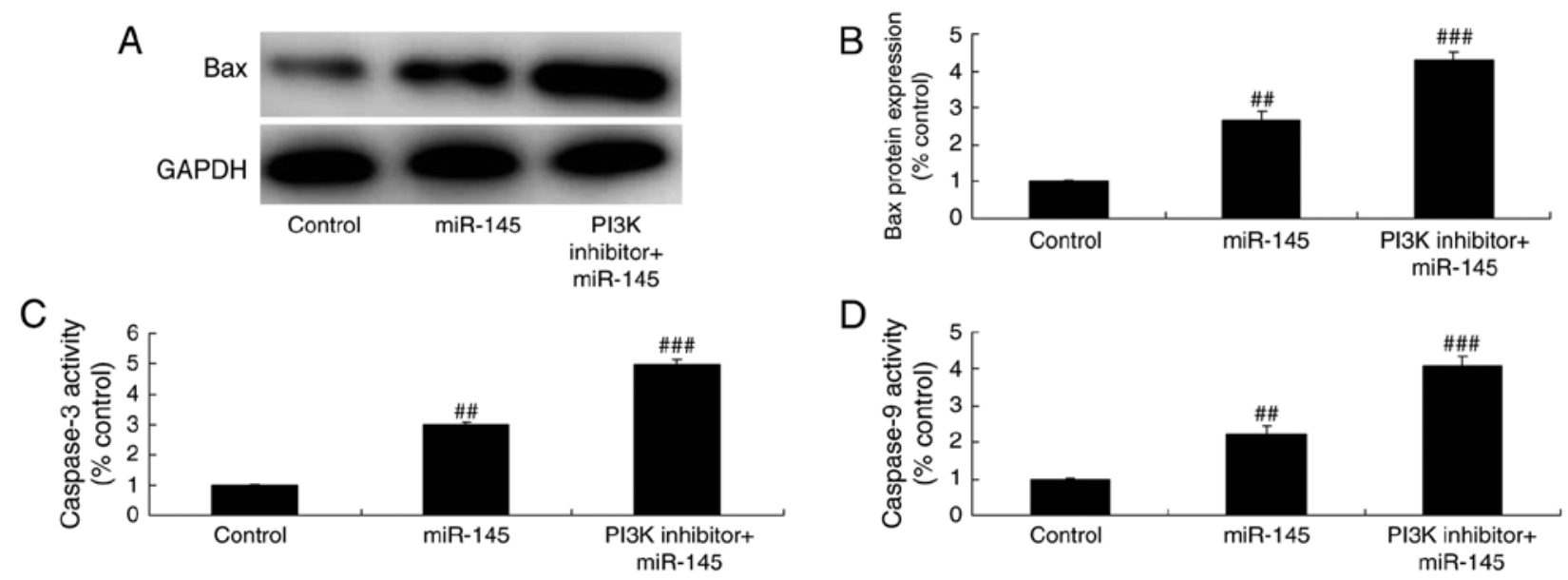

Figure 13. PI3K inhibitor suppresses caspase-3/-9 activity levels and Bax protein expression in A549 cells following miR-145 upregulation. Bax protein expression was determined using (A) western blot analysis and the results were (B) statistically analyzed. (C and D) Caspase-3/-9 activity levels in A549 cells. The results are expressed as the mean \pm standard deviation $(\mathrm{n}=3) .{ }^{\# \#} \mathrm{P}<0.01$ vs. the control group; ${ }^{\# \# \#} \mathrm{P}<0.01$ vs. the miR-145-mimic group. miR, microRNA; PI3K, phosphatidylinositol 3-kinase.

miR-145 and let-7b were underexpressed in castration-resistant prostate cancer. However, the present study only used A549 cells, which represents another limitation and in future studies it is recommended that additional cell lines are used.

In the majority of advanced NSCLC cases, the tumor pathology and EGFR status are determined using the primary tumor in the lung as opposed to the brain metastasis, as it is far easier to access and obtain (20). However, certain patients receive craniocerebral surgical resection or biopsy following the initial symptom of brain metastasis, which is able to positively confirm the diagnosis of NSCLC (21). When this occurs the brain metastasis sample may be utilized for EGFR detection. If there is consistency in the EGFR expression between the primary lesion and the brain metastasis, as determined by either diagnostic method, targeted therapies may be applied based on the results $(22,23)$. Therefore, the authors consider that miR-145 upregulation suppressed the EGFR/PI3K/AKT signaling pathway in A549 cells. Cheng et al demonstrated that miRNA-145 downregulates mucin 5AC to alleviate airway remodeling through EGFR expression (24). p-EGFR may also participate in the effects of miR-145 in A549 cells, however, only EGFR protein expression was analyzed in present study. Further studies should analyze the function of p-EGFR protein expression and the effect of miR-145 on its expression in A549 cells.

The PI3K/AKT signaling pathway has been known for over 10 years. When PI3K is phosphorylated it triggers the production of the secondary messenger phosphatidyl inositol triphosphate (PIP3) on the plasma membrane (12). PIP3 then binds with a domain in the N-terminal of AKT, while AKT translocates from the cytoplasm to the cell membrane. Activated AKT either activates or inhibits downstream target proteins through their phosphorylation and thereby regulates cell proliferation, differentiation, apoptosis and migration (25). The results of the present study demonstrated that the EGFR inhibitor suppressed the EGFR/PI3K/AKT signaling pathway and increased the anticancer effects of miR-145 upregulation in A549 cells. Zhang et al (26) reported that synthetic miR-145 expression inhibits multiple myeloma cell growth through the PI3K/AKT signaling pathway. The present study only investigated the effect of the EGFR inhibitor on miR-145 upregulation in A549 cells, therefore future studies should also explore the effect of miR-145 inhibitors combined with EGFR inhibitors in A549 cells.

All members of the PI3K family are oncogenes, which are important kinases of inositol and phosphatidylinositol (27). PI3K consists of a regulatory subunit $\mathrm{p} 85$ and a catalytic subunit p110, which promotes the phosphorylation of the 3 'hydroxyl on the inositol ring (28). AKT is a serine/threonine protein kinase with a molecular weight of $57 \mathrm{kDa}$; it is a homologue of the viral AKT oncogene in mammals (27). Activated AKT influences the active state of multiple downstream effector molecules, however these effects only occur after the PI3K/AKT signaling pathway is activated (27). AKT may inhibit cell apoptosis and activate effector molecules, including Bad, caspase-9, FKHR1 and nuclear factor- $\kappa \mathrm{B}$. AKT also participates in cell cycle regulation (it is clarified at present that AKT upregulates c-myc expression by increasing its transcription), promotes tumor angiogenesis (AKT may activate nitric oxide synthase and thereby stimulates the growth and proliferation of endothelial cells, increases vascular permeability and promotes angiogenesis following angiectasis, which provides sufficient nutrition for tumor cells) and enhances cell invasion and metastasis $(11,29)$. In addition, it was revealed that the PI3K inhibitor suppresses the PI3K/AKT signaling pathway and reversed the anticancer effects of miR-145 upregulation in A549 cells. Boufraqech et al suggest that miR-145 suppresses thyroid cancer growth and metastasis through AKT3 expression (30). The PI3K/AKT signaling pathway regulates a number of anticancer signaling pathways, including mammalian target of rapamycin, glycogen synthase kinase-3 and Bad (31). Future studies should investigate the wide variety of anticancer signaling pathways that may be affected by miR-145 in NSCLC.

In summary, the present study revealed the potential role of miR-145 in patients with NSCLC. It was also demonstrated that the EGFR/PI3K/AKT signaling pathway was inhibited 
by miR-145, which ultimately inhibited tumor development. miR-145 has been revealed as a novel potential therapy for the targeted treatment of NSCLC.

\section{Acknowledgements}

Not applicable.

\section{Funding}

No funding was received.

\section{Availability of data and materials}

The analyzed data sets generated during the study are available from the corresponding author on reasonable request.

\section{Authors' contributions}

BL designed the experiment; CMD, YXL, JCP, NG and WWQ performed the experiment; $\mathrm{BL}$ and $\mathrm{CMD}$ analyzed the data; BL wrote the manuscript. All authors read and approved the manuscript and agree to be accountable for all aspects of the research in ensuring that the accuracy or integrity of any part of the work are appropriately investigated and resolved.

\section{Ethics approval and consent to participate}

All human studies were approved by the Ethics Committee of Fourth Hospital of Hebei Medical University.

\section{Patient consent for publication}

All patients signed written informed consent forms prior to the study.

\section{Competing interests}

The authors declare that they have no competing interests.

\section{References}

1. Zhu Z, Liu W, Gillin M, Gomez DR, Komaki R, Cox JD, Mohan R and Chang JY: Assessing the robustness of passive scattering proton therapy with regard to local recurrence in stage III non-small cell lung cancer: A secondary analysis of a phase II trial. Radiat Oncol 9: 108, 2014.

2. Ahn MJ, Kim SW, Cho BC, Ahn JS, Lee DH, Sun JM, Massey D, Kim M, Shi Y and Park K: Phase II study of Afatinib as third-line treatment for patients in Korea with stage IIIB/IV non-small cell lung cancer harboring wild-type EGFR. Oncologist 19: 702-703, 2014.

3. Zhou ZY, Xu L, Li HG, Tian JH, Jiao LJ, You SF, Han ZF, Jiang Y, Guo HR and Liu H: Chemotherapy in conjunction with traditional Chinese medicine for survival of elderly patients with advanced non-small-cell lung cancer: Protocol for a randomized double-blind controlled trial. J Integr Med 12: 175-181, 2014.

4. Yamasaki M, Murakami I, Nakano K, Doi M, Kitaguchi S, Kondo T, Sakurai J, Hattori N and Arita KI: Carboplatin plus Weekly paclitaxel combined with bevacizumab as first-line treatment for non-small cell lung cancer. Anticancer Res 37: 923-928, 2017.

5. Reck M, Rodriguez-Abreu D, Robinson AG, Hui R, Csőszi T, Fülöp A, Gottfried M, Peled N, Tafreshi A, Cuffe S, et al: Pembrolizumab versus Chemotherapy for PD-L1-positive non-small-cell lung cancer. N Engl J Med 375: 1823-1833, 2016.
6. Hida T, Nakagawa K, Seto T, Satouchi M, Nishio M, Hotta K, Takahashi T, Ohe Y, Takeda K, Tatsuno M, et al: Pharmacologic study (JP28927) of alectinib in Japanese patients with ALK non-small-cell lung cancer with or without prior crizotinib therapy. Cancer Sci 107: 1642-1646, 2016.

7. Voortman J, Goto A, Mendiboure J, Sohn JJ, Schetter AJ, Saito M, Dunant A, Pham TC, Petrini I, Lee A, et al: MicroRNA expression and clinical outcomes in patients treated with adjuvant chemotherapy after complete resection of non-small cell lung carcinoma. Cancer Res 70: 8288-8298, 2010.

8. Zhan X, Wu W, Han B, Gao G, Qiao R, Lv J, Zhang S, Zhang W, Fan W, Chen H, et al: Hsa-miR-196a2 functional SNP is associated with severe toxicity after platinum-based chemotherapy of advanced nonsmall cell lung cancer patients in a Chinese population. J Clin Lab Anal 26: 441-446, 2012.

9. Neal JW, Dahlberg SE, Wakelee HA, Aisner SC, Bowden M, Huang Y, Carbone DP, Gerstner GJ, Lerner RE, Rubin JL, et al: Erlotinib, cabozantinib, or erlotinib plus cabozantinib as second-line or third-line treatment of patients with EGFR wild-type advanced non-small-cell lung cancer (ECOG-ACRIN 1512): A randomised, controlled, open-label, multicentre, phase 2 trial. Lancet Oncol 17: 1661-1671, 2016.

10. Planken S, Behenna DC, Nair SK, Johnson TO, Nagata A, Almaden C, Bailey S, Ballard TE, Bernier L, Cheng H, et al: Discovery of $N$-((3R,4R)-4-fluoro-1-(6-((3-methoxy-1-methyl$1 H$-pyrazol-4-yl)amino)-9-methyl-9H-purin-2-yl)pyrrolidine-3-yl) acrylamide (PF-06747775) through structure-based drug design: A high affinity irreversible inhibitor targeting oncogenic EGFR mutants with selectivity over wild-type EGFR. J Med Chem 60: 3002-3019, 2017.

11. Zhang Q, Zhu H, Xu X, Li L, Tan H and Cai X: Inactivated Sendai virus induces apoptosis and autophagy via the $\mathrm{PI} 3 \mathrm{~K} / \mathrm{Akt} / \mathrm{mTOR} / \mathrm{p} 70 \mathrm{~S} 6 \mathrm{~K}$ pathway in human non-small cell lung cancer cells. Biochem Biophys Res Commun 465: 64-70, 2015.

12. Lin $\mathrm{CH}$, Lin HH, Kuo CY and Kao SH: Aeroallergen Der p 2 promotes motility of human non-small cell lung cancer cells via toll-like receptor-mediated up-regulation of urokinase-type plasminogen activator and integrin/focal adhesion kinase signaling. Oncotarget 8: 11316-11328, 2017.

13. Qiao L, Wang J, Long G and Jiang Y: Sequential treatment of tyrosine kinase inhibitor and platinum-based doublet chemotherapy on EGFR mutant non-small cell lung cancer: A meta-analysis of randomized controlled clinical trials. Onco Targets Ther 10: 1279-1284, 2017.

14. Uchibori K, Inase N, Araki M, Kamada M, Sato S, Okuno Y, Fujita $\mathrm{N}$ and Katayama R: Brigatinib combined with anti-EGFR antibody overcomes osimertinib resistance in EGFR-mutated non-small-cell lung cancer. Nat Commun 8: 14768, 2017.

15. Guo Y, Sun W, Gong T, Chai Y, Wang J, Hui B, Li Y, Song L and Gao Y: miR-30a radiosensitizes non-small cell lung cancer by targeting ATF1 that is involved in the phosphorylation of ATM. Oncol Rep 37: 1980-1988, 2017.

16. Fang C, Chen YX, Wu NY, Yin JY, Li XP, Huang HS, Zhang W, Zhou HH and Liu ZQ: MiR-488 inhibits proliferation and cisplatin sensibility in non-small-cell lung cancer (NSCLC) cells by activating the eIF3a-mediated NER signaling pathway. Sci Rep 7: 40384, 2017.

17. Wu X, Long L, Liu J, Zhang J, Wu T, Chen X, Zhou B and Lv TZ: Gambogic acid suppresses inflammation in rheumatoid arthritis rats via PI3K/Akt/mTOR signaling pathway. Mol Med Rep 16: 7112-7118, 2017.

18. Mulvenna P, Nankivell M, Barton R, Faivre-Finn C, Wilson $P$, McColl E, Moore B, Brisbane I, Ardron D, Holt T, et al: Dexamethasone and supportive care with or without whole brain radiotherapy in treating patients with non-small cell lung cancer with brain metastases unsuitable for resection or stereotactic radiotherapy (QUARTZ): Results from a phase 3, non-inferiority, randomised trial. Lancet 388: 2004-2014, 2016.

19. Zhu J, Wang S, Zhang W, Qiu J, Shan Y, Yang D and Shen B: Screening key microRNAs for castration-resistant prostate cancer based on miRNA/mRNA functional synergistic network. Oncotarget 6: 43819-43830, 2015.

20. Marquez-Medina D and Popat S: Eventual role of EGFR-tyrosine kinase inhibitors in early-stage non-small-cell lung cancer. Future Oncol 12: 815-825, 2016.

21. Wang W, Jiang X, Song Z and Zhang Y: Patients harboring EGFR mutation after primary resistance to crizotinib and response to EGFR-tyrosine kinase inhibitor. Onco Targets Ther 9: 211-215, 2016. 
22. Nand M, Maiti P, Pant R, Kumari M, Chandra S and Pande V: Virtual screening of natural compounds as inhibitors of EGFR 696-1022 T790M associated with non-small cell lung cancer. Bioinformation 12: 311-317, 2016.

23. Sheng Z and Zhang Y: EGFR-TKIs combined with chemotherapy versus EGFR-TKIs single agent as first-line treatment for molecularly selected patients with non-small cell lung cancer. Med Oncol 32: 420, 2015

24. Cheng Z, Dai LL, Wang X, Jia LQ, Jing XG, Li PF, Liu M, Wang $\mathrm{H}$ and An L: MicroRNA-145 down-regulates mucin 5AC to alleviate airway remodeling and targets EGFR to inhibit cytokine expression. Oncotarget 8: 46312-46325, 2017.

25. Kim N, Jeong S, Jing K, Shin S, Kim S, Heo JY, Kweon GR, Park SK, Wu T, Park JI, et al: Docosahexaenoic acid induces cell death in human non-small cell lung cancer cells by repressing mTOR via AMPK activation and PI3K/Akt inhibition. Biomed Res Int 2015: 239764, 2015.

26. Zhang Q, Yan W, Bai Y, Xu H, Fu C, Zheng W, Zhu Y and Ma J: Synthetic miR-145 mimic inhibits multiple myeloma cell growth in vitro and in vivo. Oncol Rep 33: 448-456, 2015.
27. Vansteenkiste JF, Canon JL, De Braud F, Grossi F, De Pas T, Gray JE, Su WC, Felip E, Yoshioka H, Gridelli C, et al: Safety and efficacy of Buparlisib (BKM120) in patients with PI3K pathway-activated non-small cell lung cancer: Results from the phase II BASALT-1 study. J Thorac Oncol 10: 1319-1327, 2015.

28. Wang Z, Shen Z, Li Z, Duan J, Fu S, Liu Z, Bai H, Zhang Z, Zhao J, Wang X, et al: Activation of the BMP-BMPR pathway conferred resistance to EGFR-TKIs in lung squamous cell carcinoma patients with EGFR mutations. Proc Natl Acad Sci USA 112: 9990-9995, 2015.

29. Zhang XY, Kuang JL, Yan CS, Tu XY, Zhao JH, Cheng XS and Ye XQ: NRSN2 promotes non-small cell lung cancer cell growth through PI3K/Akt/mTOR pathway. Int J Clin Exp Pathol 8: 2574-2581, 2015.

30. Boufraqech M, Zhang L, Jain M, Patel D, Ellis R, Xiong Y, He M, Nilubol N, Merino MJ and Kebebew E: miR-145 suppresses thyroid cancer growth and metastasis and targets AKT3. Endocr Relat Cancer 21: 517-531, 2014.

31. Pérez-Ramirez C,Cañadas-Garre M,Molina MA, Faus-Dáder MJ and Calleja-Hernández MA: PTEN and PI3K/AKT in non-smallcell lung cancer. Pharmacogenomics 16: 1843-1862, 2015. 